\title{
El jade y las piedras verdes en Teotihuacan, México
}

\author{
Leila Maria França*
}

\begin{abstract}
FRANÇA, L.M. El jade y las piedras verdes en Teotihuacan. Revista do Museu de Arqueologia e Etnologia, São Paulo, 20: 327-344, 2010.
\end{abstract}

Resumo: $\mathrm{O}$ jade foi um dos materiais mais valiosos na Mesoamérica, onde era amplamente usado na elaboração de imagens de deuses, objetos de culto, joias e ornamentos, entre muitos outros. Em Teotihuacan, o jade e seus similares - as pedras verdes - tiveram um papel fundamental na ornamentação da elite e no culto, plasmando conceitos fundamentais da cosmovisão e da religião estatal. Este artigo trata de detalhar os aspectos do simbolismo do jade em Teotihuacan, sua importância ideológica e o controle sobre sua obtenção e produção de artefatos, através do estudo dos artefatos de jade e pedras verdes conservados na Ceramoteca da Zona de Monumentos Arqueológicos de Teotihuacan.

Palavras-chave: Teotihuacan - Mesoamérica - México - Jade - Ideologia.

E 1 jade fue un elemento esencial en la religión y en la materialización de la cosmovisión de distintas sociedades mesoamericanas. La adoración de la gema verde preciosa se remonta al periodo Formativo en sociedades pre-Olmecas (Garber et alii 1993) y puede ser considerada un fenómeno universal en esta área, particularmente asociada a nociones de agua, vida y fertilidad (França 2005; Tibón 1983; Thouvenot 1982).

En las distintas sociedades mesoamericanas, en mayor o menor grado, el jade (la jadeita un silicato de aluminio - y los minerales asociados que integran las rocas de jadeita) fue

$\left.{ }^{*}\right)$ Investigadora de Posdoctorado en el Museu de Arqueologia e Etnologia de la Universidad de São PauloUSP, con el Proyecto: "Las rutas del jade en Mesoamérica: el intercambio de larga distancia y el poder estatal en Teotihuacan, México”, <lefanca@usp.br> reemplazado por otras piedras y minerales más accesibles, sin perder su simbolismo. Dicho fenómeno ha llevado los especialistas a utilizar el término "jade cultural" o "jade social" (Lange 1993: 1) para referirse a esa amplia variedad de materiales utilizados en la elaboración de adornos, figurillas, cuentas, collares y muchas otras formas que tenían en común el pertenecer a una esfera de prestigio y sobre todo, sagrada.

Sin embargo, estudios demuestran que aunque el uso del jade estuvo presente en las diversas sociedades mesoamericanas y con fines aparentemente similares, cada cultura presentó estilos y sobre todo usos particulares asociados a los distintos contextos socioculturales. No trataremos aquí de la cuestión estilistica ya que es un tema extenso que sobrepasa los objetivos de este articulo. En lo referente a su uso, en el área maya, el jade tuvo un carácter predominantemente politico, bajo la forma de adornos y 
placas y su simbolismo estaba ligado a la expresión máxima del poder real, el ahau (Taube 2005:23,27; Freidel 1993: 155-162). Entre los Olmecas, se ha observado un uso ritual muy relevante, en lo cual se ofrecia diversos tipos de objetos como hachas, adornos, figurillas, figuras zoomorfas, canoas a los seres sobrenaturales (Miller 1991: 24-30; Garber et al.: 213-215). En Costa Rica, el uso del jade y similares fue predominantemente social e funerario (Lange 1993: 4; Garber et alli 1993:225; Stone 1993:143).

Entre los mexicas, el uso del jade social o chalchihuitl ha sido muy amplio, bajo un gran número de formas y contextos, entre ellos el uso doméstico, social y sobretodo el ritual. En un estudio sobre las piedras verdes en las ofrendas del Templo Mayor de Tenochtitlan, hemos demostrado la extrema importancia de su simbolismo sagrado que, más allá de una simple representación del agua, vida y fertilidad, materializaba infinitas ideas y conceptos asociados al inframundo, a los lugares miticos, los antepasados y la conservación del "alma" y la unión de las dos mitades del cosmos, responsable por el origen y dinámica de la vida (França 2005: 230-300). En algunos casos, esa importancia estaria asociada al hecho de que los objetos elaborados con la "gema hecha oración" o "la piedra que vive y da vida" (Tibón 1983: 15, 26) probablemente representaba las fuerzas anímicas, sobretodo el tonalli y el teyolía - razón por la cual se la usaba en la boca de los muertos o en el pecho de las imágenes de los dioses (França 2005: 37; Tibón 1983: 30-32; Hernández Pons 1982).

En Teotihuacan no fue diferente. Los testimonios arqueológicos nos enseñan que el jade y las piedras verdes fueron muy estimados y preferentemente usados en contextos de gran importancia social y ritual en esa importante sociedad que floreció en el llamado Periodo Clásico mesoamericano (200-800 d.C., Tabla I). Imágenes de probables deidades o antepasados elaboradas en bloques de piedra verde han sido encontradas en importantes puntos de la urbe, donde seguramente se practicaba la religión estatal; y lo más interesante es que algunas de ellas presentaban rasgos olmecas, lo que podria indicar (al igual que entre los mexicas y otros pueblos de Mesoamérica) su relación con el culto a los ancestros (Jarquín 2002: 201, 202, 276; Pasztory 1992: 307).

Tabla I

\begin{tabular}{lcc}
\hline \multicolumn{3}{c}{ Cronología de Teotihuacan } \\
\hline \hline \multicolumn{1}{c}{ Fase } & Fechas & \multicolumn{1}{c}{ Periodo } \\
\hline Patlachique & $150-0 \mathrm{aC}$ & Formativo Terminal \\
Tzacualli & $0-150 \mathrm{dC}$ & Formativo Terminal \\
Miccaotli & $150-200 \mathrm{dC}$ & Formativo Terminal \\
Tlamimilolpa & $200-400 \mathrm{dC}$ & Clásico Temprano \\
Xolalpan & $400-550 \mathrm{dC}$ & Clásico Temprano \\
Metepec & $550-650 \mathrm{dC}$ & Clásico Tardío \\
\hline
\end{tabular}

Las máscaras teotihuacanas son otro ejemplo del posible simbolismo de las piedras verdes. No es coincidencia el hecho de que la mayoría de las máscaras - que tradicionalmente tenian un uso funerario - hayan sido hechas de este material: éstas posiblemente tenían una función de preservar la esencia del muerto, tal como propuesto por A. Headrick (1999: 78-83), y eso es más claro cuando tomamos el ejemplo de máscaras que presentaron pintura e incrustación de concha, obsidiana y otros materiales, lo que indica que la piedra verde era más una necesidad funcional que estética.

Uno de los primeros hechos que llaman nuestra atención es la variedad de objetos elaborados en estas materias primas, obtenida a partir de la utilización de un conjunto de técnicas que incluia, el picoteamento, la percusión, el corte, el asseramiento, el raspado, la perforación, la incisión, el pulido y el bruñido (Mirambell 1968; Foshag 1954-55; González y Olmedo Vera 1986b).

En un levantamiento de estos materiales realizado en la Ceramoteca de la Zona Arqueológica de Teotihuacan, especificamente aquellos registrados en inventario (la mayor parte compuesta de objetos enteros y algunos fragmentados), hemos observado una amplia variedad de objetos en lo referente a su forma/ función. Son objetos provenientes de diversos puntos de la urbe y recuperados por diversos proyectos desde los años 60 hasta los salvamientos más recientes (Mapa). Desgraciadamente, parte 


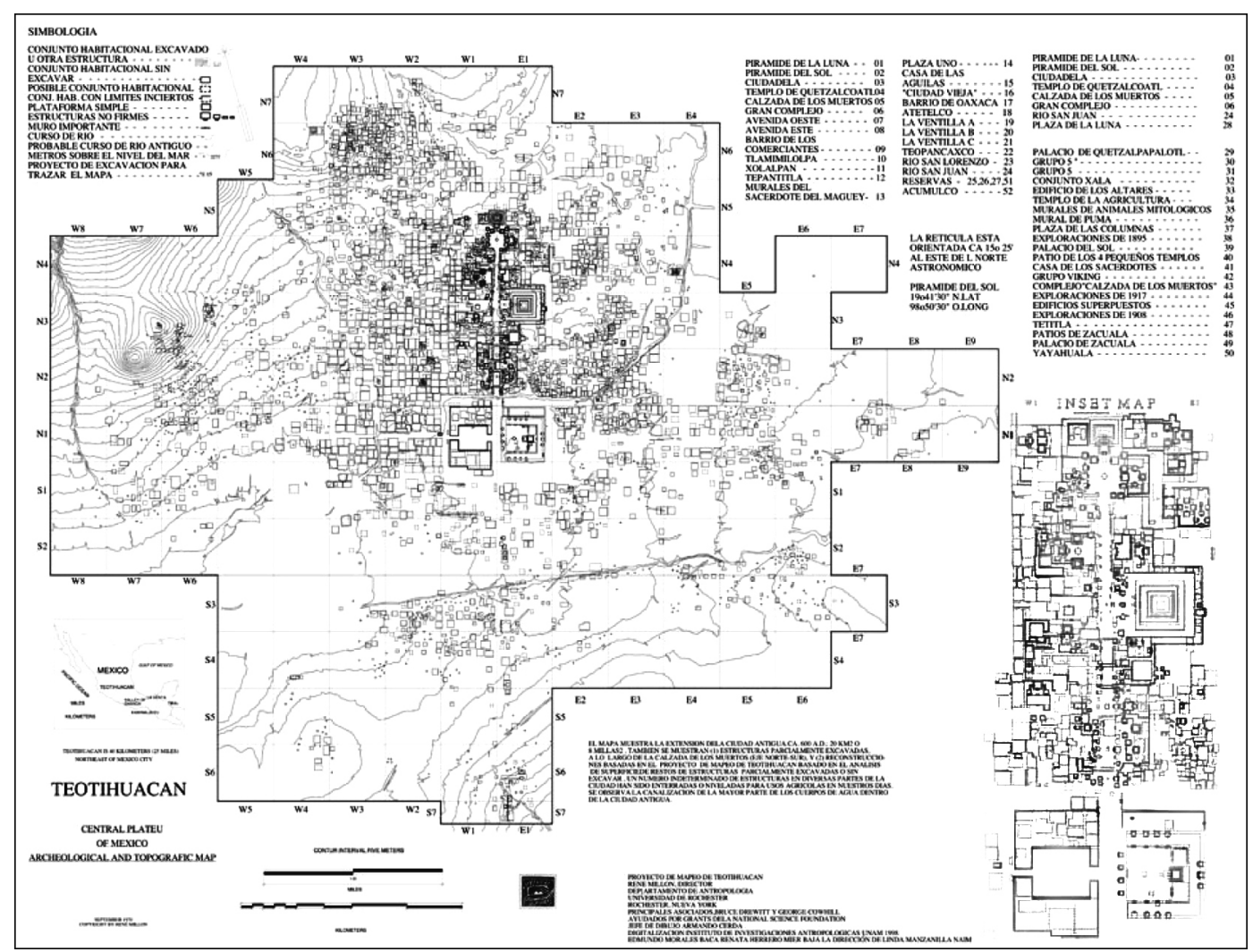

Mapa de Teotihuacan. Fuente: Teotihuacan Mapping Project, R. Millón, 1973.

del acervo no tiene registro de procedencia, lo que impide hacer un estudio sistemático de patrones contextuales. Aún así, los contextos disponibles son suficientes para sacar una serie de informaciones importantes acerca del significado de este material en la sociedad teotihuacana.

Los materiales pueden ser clasificados en cuatro grandes grupos o "temas" de acuerdo a su función primaria: simbólico, atavio, utilitarios y elemento arquitectónico (Tabla II). ${ }^{1}$ Hemos identificado 34 tipos de objetos según su forma/función:

1. El primer grupo, de los objetos simbólicos está integrado por artefactos que no tienen una función primaria identificable, sino

(1) Algunos objetos de forma indefinida no pudieron ser identificados así que no se pudo clasificarlos en uno de estos temas. exclusivamente simbólica o que, aunque recuerden objetos utilitarios, fueron hechos exclusivamente para el uso ritual, como es el caso de las llamadas "miniaturas votivas". Dentro de ese grupo están las figuras antropomorfas, máscaras, cabezas antropomorfas, figuras zoomorfas, conos con decoración incisa, esferitas, un fragmento de cuenco, un fragmento de vaso Tlaloc, un objeto fálico, aplicaciones (incluyendo “ojos" de imágenes), esculturas simbólicas, y dos hachas miniatura.

2. En el segundo grupo, de los atavíos y adornos - objetos que tenian como función la ornamentación y la visualización del estatus social - están las cuentas, collares, orejeras y sus tapones, pendientes, narigueras estilo "mariposa" o "crótalo de serpiente", pectoral, incrustaciones de mosaico e incrustaciones dentales.

3. El tercer grupo incluye los objetos de uso utilitario, la mayor parte herramientas: hachas, gubias, un desfibrador, un percutor, un 
Tabla II

\begin{tabular}{lcccc}
\hline \multicolumn{5}{c}{ Categorías de objetos por temas } \\
\hline \hline \multicolumn{1}{c}{ Simbólico } & Atavío & Utilitarios & $\begin{array}{c}\text { El. Arquite } \\
\text { Ctónico }\end{array}$ & Desconocido \\
\hline Figura antropomorfa & Cuenta & Hacha & Estela & Objeto irregular \\
Máscara & Collar & Gubia & Almena & Objeto rectangular \\
Cabeza Antropomórfica & Orejera & Desfibrador & Laja & - \\
Figura zoomorfa & Tapón (orejera) & Percutor & Escultura & - \\
Cono & Pendiente & Soporte & - & - \\
Esferita & Nariguera & Pulidor & - & - \\
Cuenco & Pectoral & Raspador & - & - \\
Vaso Tlaloc & Incrustación mosaico & Mano de metate & - & - \\
Objeto fálico & Incrustación dental & - & - & - \\
Aplicación & - & - & - & - \\
Esculturas simbólicas & - & - & - & - \\
Hacha miniatura & - & - & - & - \\
Bigotera Tlaloc & - & - & - & - \\
\hline
\end{tabular}

pulidor, un raspador, una mano de metate y soportes.

4. Dentro del cuarto grupo - "elemento arquitectónico" - fueron registrados lajas, esculturas, una almena y una estela.

Dentro de la clasificación realizada, hay cuatro objetos cuya función no se pudo determinar, razón por la cual fueron clasificados bajo la etiqueta de "Desconocido".

\section{Objetos simbólicos}

Entre los objetos de uso simbólico de esta colección, algunos llaman nuestra atención y las figuras antropomorfas y máscaras son los más notables y más frecuentes. Elaborados en diferentes tipos de piedra verde, éstos presentan una gran variación en sus formas y tamaños y pueden presentar igualmente estilos diferentes.

Las figuras antropomorfas, las más numerosas entre los objetos simbólicos, varian en general entre 3 y $48 \mathrm{~cm}$. de largo y son de "estilos" distintos: algunas presentan rasgos olmecas (Fig. 1) del llamado estilo "olmecóide" o "Teotihuacanguerrero" (Covarrubias 1961: 121-122), otras el estilo teotihuacano, pero lo más frecuente, es el estilo mezcala, caracterizado por los rasgos incisos esquemáticos. Dos de los ejemplares más impresionantes son de gran dimensión y elaborados en estilo olmeca-guerrero y teotihuacano-guerrero y como particularidad presentan una oradación en el pecho en donde originalmente tenían insertados discos de pizarra. Dichas esculturas fueron localizadas en el Pasillo entre los conjuntos E y F del Conjunto 1-D en el lado norte del Templo de Quetzalcóatl (Jarquín 2002:181-182).

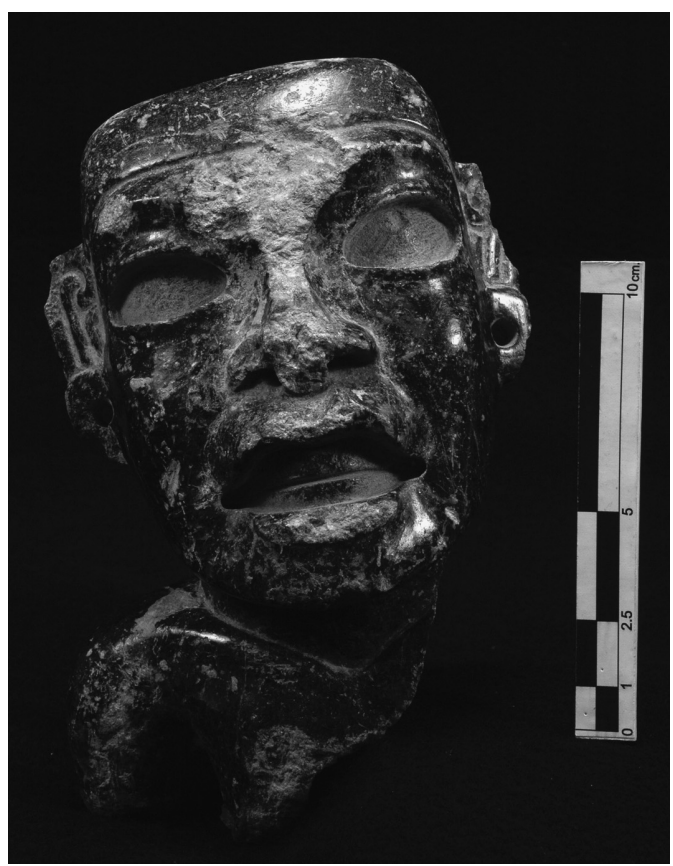

Fig.1. Figura antropomorfa con rasgos "olmecóides", elaborada en serpentina. Templo de los Sacerdotes, Pirámide del Sol, Teotihuacan. 
Otras figuras de menor tamaño fueron encontradas en diversos contextos: en el propio conjunto 1-D y en otros puntos de La Ciudadela (una en la ofrenda 7, en la estructura Cuadrángulo) en la Ventilla, Pirámide de la Luna, Plaza de la Luna y Calle de Muertos. Desgraciadamente, no encontramos registros de ubicación especifica para muchas de ellas, aunque sabemos sobre su presencia en ofrendas (Cabrera Castro 2002: 112-113; Cabrera Cortes 1995; Rubin de la Borbolla 1974: 66).

La máscara es una categoria de objeto en que se destaca la lapidaria de Teotihuacan, algunas de tamaño impresionante. De los ejemplares examinados, pocos tienen procedencia, siendo algunos provenientes de la Calle de Muertos, uno de la Ventilla, otro de de los Edificios Superpuestos y otro más del Conjunto NW del Río San Juan. Sin embargo, sabemos que varias de las máscaras teotihuacanas fueron recuperadas en áreas a lo largo de la Calle de Muertos durante las excavaciones del los años 60 (Headrick 1999: 74,79). Muchas fueron elaboradas en diorita gris oscuro, pero la mayor parte sigue siendo de piedra verde.

Otra categoria es la de las figuras zoomorfas y entre las tres registradas están dos representaciones de serpientes y una de felino, animales muy significativos dentro de la cosmovisión mesoamericana y en el sistema de representación teotihuacano, sobretodo en la pintura mural. El felino fue recuperado en el cuadro N1W1 en el área del Gran Conjunto.

Algunos de los objetos de piedra verde más sorprendentes en Teotihuacan son 18 conos (17 con decoración incisa y 1 sin decoración) encontrados en la Ofrenda 14 en el Templo de Quetzalcóatl (Fig. 2) de los cuales ocho estaban disponibles en la Ceramoteca. No se conoce objetos similares en Teotihuacan y tampoco en toda el área mesoamericana. Su ubicación en una ofrenda dedicatoria en el mero centro del

Templo y en un entierro múltiple de veinte individuos adultos masculinos - particularmente asociados a un único individuo - indica su excepcionalidad (Cabrera Cortés 1995: 130). Según Cabrera Cortés, probablemente represente cerros que remiten a la idea de fertilidad (1995: 304).

Entre los objetos simbólicos está la mitad de un vaso Tlaloc - similar a los Jarros Tlaloc de tezontle (roca vulcánica) de las ofrendas del Templo Mayor - elaborado en tecalli (ónix) verdoso y que presenta restos de pigmento azul, blanco y amarillo. Un segundo atributo de Tlaloc es una bigotera, muy bien diseñada con decoración incisa elaborada en piedra verde clara, desgraciadamente, sin procedencia.

Otra categoria que llama la atención son las aplicaciones tipo "ojo". Identificado en ciertos casos como "botón" en miniatura, es muy posible que se tratara de ojos de imágenes de deidades por su tamaño y similitud, pero también por una posible relación con la práctica del Posclásico Tardio de poner ojos de piedra verde en las imágenes de las deidades (França 2005: 201; Durán 1984, I: 24, 38) o aún en Teotihuacan, donde se incrustaba piedras preciosas - probablemente jadeita - en las imágenes de deidades (Jarquín 2002: 199). Uno de ellos presentó pigmento rojo y fue excavado en el Entierro 7 de San Sebastian Xolalpan.

El fragmento de cuenco procedia de la Calle de Muertos y el objeto fálico fue localizado en la habitación 1 del Grupo D del Conjun- 
to $1 \mathrm{D}$, asociado a un brasero ceremonial, cuentas de piedra verde y pigmento rojo. Las cabezas antropomorfas y esferitas no presentaran registro de procedencia

Las hachas miniatura han sido clasificadas entre los objetos simbólicos, ya que su tamaño reducido indica un uso especificamente ritual. Diferentemente de las demás, no presentan huellas de utilización y aunque no conocemos sus contextos de deposición, es muy posible que provengan de alguna ofrenda o entierro. Sin embargo, los datos revelan que herramientas con huellas de uso también eran depositadas en ofrendas o entierros, como veremos más adelante.

\section{Atavíos}

El objeto más abundante en los diversos contextos de la urbe son las cuentas. La verdad, se trata de un patrón mesoamericano, ya que la cuenta es una categoria abundante en los contextos arqueológicos de esta superárea, debido a su importante función y simbolismo. Las cuentas de Teotihuacan son en su gran mayoria globulares pero también hay unas pocas de otras formas: tubulares, planas, cuadrangulares, irregulares, y en forma de calabaza. Muchas de las cuentas la muestra estudiada fueron recuperadas en entierros $\mathrm{u}$ ofrendas en La Ciudadela, La Ventilla, San Sebastián Xolalpan, Conjunto NW del Río San Juan y al norte del Barrio Oaxaca.

Las cuentas también pueden aparecer bajo la forma de collar, que en el contexto arqueológico se puede identificar por su proximidad con el cuello y el tórax de los esqueletos, y obviamente por la cantidad de cuentas y en algunos casos por las formas y combinaciones de las mismas. De los 6 sartales registrados como "collares" uno procede de una "posible" ofrenda en el Conjunto 1D y otro del Entierro 17 de la Ventilla.

Otro tipo de objeto muy significativo son las orejeras circulares de piedra verde, con un promedio de $5 \mathrm{~cm}$. de diámetro y la mayoría de ellas hechas en piedra verde clara - algunas de jadeita verde manzano - y se caracterizan por su buen acabado y brillo. Entre estas se destaca un par de orejeras en forma de flor que marcan un quincunce, recuperados en el entierro 17, en el Palacio de Atetelco, aunque, desgraciadamente, no encontramos otros detalles contextuales. Algunos ejemplares fueron elaborados en rocas más rudas y pesadas y son de tamaño grande, alcanzando hasta $8,5 \mathrm{~cm}$. de diámetro, lo que indica que probablemente eran objetos votivos o parte de la indumentaria de imágenes. Otros ejemplares presentan un diámetro reducido, aunque elaboradas en jadeita como es el caso de un par de orejeras de La Ventilla, o de otra en forma de flor que se encuentra en la Vitrina 3 de la Sala 4 del Museo de Sitio. Las demás fueron recuperadas en varios puntos como la Plaza de la Luna, Calle de Muertos, Conjunto 1D, Cuartos Adosados. Además, algunos ejemplares provienen de entierros de Atetelco, del Conjunto NW y de la estructura Cuadrángulo en La Ciudadela. Sabemos que juntamente con otros adornos, las orejeras son muy frecuentes en las ofrendas dedicatorias en el Templo de Quetzalcóatl y la Pirámide de la Luna (Cabrera Castro y Serrano Sánchez 2003: 352, 360, 362); Cabrera Cortes 1995; Sugiyama 1989: 91, 102; Rubin de la Borbolla 1974: 64, 66).

Dichos atavios tenían un tapón para realizar el encaje en la oreja de su usuario y algunos ejemplares han sido igualmente recuperados.

Otra categoria de atavio muy frecuente en la gran urbe son los pendientes. Algunos de los pendientes revisados tienen forma triangular con muesca y bordes biselados, rectangulares o irregulares. Entre estos últimos podemos destacar un par de pendientes de jadeita, recuperados en el Entierro 1 de Totometla, los cuales, aunque presentan un excepcional pulido, conservan la forma original de la roca - posiblemente por el valor y el simbolismo que eran atribuidas a las piedras en bruto (França, 2005: 227, 228; Rubin de la Borbolla 1974: 67). Otro ejemplar que llama la atención es un pendiente fragmentado en forma rectangular elaborada en el más rico jade azul excavado en La Ciudadela (Fig. 3). Algunos ejemplares son provenientes de ofrendas en el conjunto Plaza Oeste (antropomorfo), en la estructura Cuadrángulo (en forma de mariposa) y el Conjunto 1D (en forma de flor). 


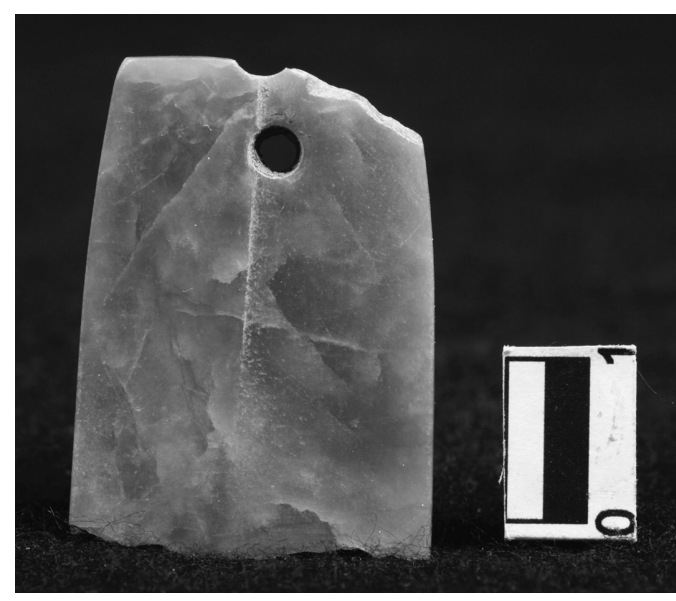

Fig. 3. Pendiente en jade verde azulado. Conjunto Pasillo, La Ciudadela, Teotihuacan.

Las tres narigueras examinadas tienen forma de "mariposa" o "crótalo de serpiente", una de ellas con presencia de pigmento negro y rojo y fueron todas elaboradas en piedra verde de calidad, probablemente fuchsita. Una de ellas procede de un entierro de la fase Xolalpan en Acatitla. El segundo ejemplar fue excavado en un canal de drenaje en el sector N2E2 a noreste de La Ciudadela y para el tercer no hay registro proveniencia.

Entre cuatro placas examinadas, una fue recuperada en la Calle de Muertos y otra en La Ventilla. Una de ellas, sin procedencia, tiene una forma trapezoidal, muy pulida, a manera de espejo.

Las incrustaciones, varias de ellas con presencia de pigmento rojo (algunas con blanco), son otra categoría muy interesante. Llaman la atención dos grupos de incrustaciones de mosaico, uno con 29 piezas y con restos de pigmento rojo, sin procedencia, y otro de 55 teselas provenientes del entierro 71 en el Conjunto 1D. Según Jarquín se trata posiblemente de un pectoral en forma de quincunce (2002). Las incrustaciones dentales fueron recuperadas en el
Entierro 27 de la estructura 19 del Sector N1E5, asociadas a un adulto joven del sexo masculino, con mutilación e incrustación dental (Fig. 4). Dichas piezas presentaban pigmento rojo y estaban asociadas a punta de proyectil de obsidiana, navaja, 2 orejeras y una nariguera "crótalo de serpiente" y 21 cuentas de piedra verde. El entierro fue fechado en el Tlamimilolpa Tardio y su presencia en el entierro, según Gazzola (2000: 150) podría indicar la ocupación de los habitantes de este sector.

\section{Utilitarios}

En cuanto a los objetos utilitarios de piedra verde, la categoría más común en la muestra es el hacha, la mayor parte de ellas con rasgos de utilización, y en la mayoria de los casos, desgraciadamente, sin procedencia (Fig. 5). Ya que muchos ejemplares están elaborados en rocas de otros colores, sobretodo gris y negro - y mediante la ausencia de registros, no sabemos si el uso de la piedra verde involucraba alguna intención. La mayor parte no tiene procedencia, algunas de ellas por haber sido recuperadas en rescates anteriores a los años 80. Dos ejemplares fueron recuperados en la Ofrenda 3, del Conjunto NW del Rio San Juan y presentan rasgos de utilización, un en la Ventilla, Cala IV, cuadros D, E, 33-35.

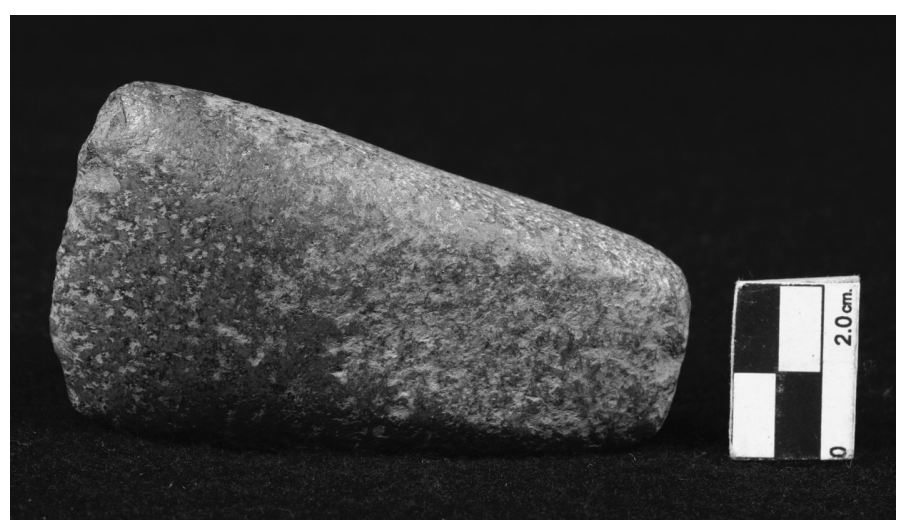

Fig. 4. Hacha con rasgos de uso y presencia de pigmentos de varios colores, Teotihuacan. Sin contexto. 


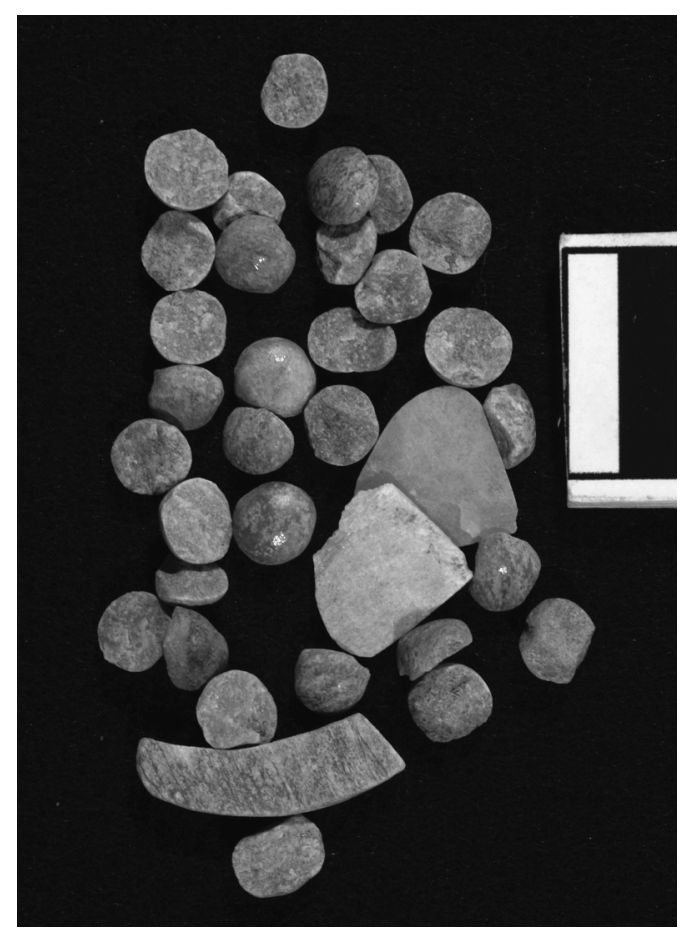

Fig. 5. Incrustaciones dentales con pigmento rojo. Área del Cuartel Militar, Entierro, 27. Teotihuacan.

Entre las gubias, una presentó rasgos de utilización. La única con proveniencia es un ejemplar oxidado, recuperado en el conjunto Yayahuala.

Otra categoria es la de los pulidores, uno de los cuales fue excavado en el Palacio 3 de la Plaza de la Luna, un segundo ejemplar en el Pozo 5C en el Barrio Oaxaca y otro más en el cuadro N3E2, a este de la Pirámide del Sol.

Entre los demás utilitarios, el único percutor examinado estuvo asociado al Entierro 5 de la Ventilla; dos soportes son provenientes del mismo barrio y otro de la Calle de Muertos; dos desfibradores, uno excavado en la Plaza Anexa, La Ciudadela. La mano de metate y un raspador no presentan procedencia.

Como dijimos, no sabemos si el uso de piedras de color verde para estos objetos es un mero azar o si había una intención. Sin embargo, hay un dato curioso que puede indicar una intención: varios ejemplares presentan pigmento, en la mayoría de los casos, rojo, lo que probablemente no se debe al azar, ya que la aplicación de pigmento rojo sobre la piedra verde tiene un significado simbólico muy específico del cual trataremos adelante.

\section{Elementos arquitectónicos}

Como se dijo, los objetos de esta categoria hacian parte de la arquitectura de la urbe, clasificados como estelas, esculturas, una laja y una almena. Una laja fue recuperada en el Palacio 3 en la Plaza de la Luna, y algunas esculturas (cinco) y dos estelas proceden del "Patio de las Esculturas".

\section{Discusión}

Como se ha dicho, el uso de artefactos de piedras verdes es un fenómeno "universal" en Mesoamérica, y muchas caracteristicas de ese uso son compartidas por las varias sociedades mesoamericanas a lo largo del tiempo. En cuanto al simbolismo, el eje común es la relación fundamental con aspectos de la cosmovisión ligados a la mitad fría del cosmos, como el simbolismo acuático y de la fertilidad, en que éstos materiales plasman conceptos ligados a la vida, el agua, la vegetación, el nacimiento, el espíritu de los ancestros, entre otros. Entre los mexicas, la corriente fría del malinalli, punto de encuentro del ámbito subterráneo y celestial del universo, era verde o azul, y en los códices es identificado con el chalchihuitl (López Austin 1994: 84, 93)

Sin embargo, además de la temática general, estos objetos se diferencian en las distintas culturas en lo referente a su estilo y patrones de uso, siendo que, como dijimos, entre los mayas, el jade y sus similares presentaron un uso más social, mientras que para los Olmecas observamos un uso de carácter más ceremonial. Si es verdad que esta superárea compartió una cosmovisión común que llamamos "cosmovisión mesoamericana”, también se admite que ésta presentaba matices locales en razón de los rasgos sociales, politicos, ideológicos e históricos de determinada sociedad (López Austin 1996: 472). Dichos simbolismos pueden variar en la misma medida. 
Parece claro, por lo tanto, que aunque encontremos patrones muy parecidos en el registro arqueológico, el significado de las piedras verdes entre los teotihuacanos y mexicas no fue lo mismo. Sin embargo, el hecho de que se trate de un patrón mesoamericano nos da algunos elementos para reflexión, para allá del propio contexto de los materiales. Bajo esta condición, es decir, a la luz de los contextos y de la comparación con los datos arqueológicos de otras sociedades, creemos que se puede recurrir eventualmente a las fuentes escritas del siglo XVI, siempre con mucho cuidado y evitándose una comparación directa con los datos de una sociedad mucho anterior.

Si para Teotihuacan no podemos contar con la documentación escrita, los materiales y sus contextos sí confirman dicha asociación de las piedras verdes con el inframundo y los temas de la fertilidad. Además de la propia pintura mural en la cual podemos ver a los dioses que proveen los bienes y la fertilidad bajo la representación de objetos de "jade" - asi como los círculos de chalchihuitl (un símbolo acuático) presentes en varios puntos de la ciudad, asociado a otros elementos del inframundo -, los propios objetos nos dan informaciones importantes, tanto por su forma como por su contexto.

El material estudiado nos brinda muchas posibilidades de estudio. Sin embargo, por una cuestión de espacio, privilegiamos el tema del simbolismo y algunas consideraciones sobre su uso oficial y cronología.

\section{La piedra verde y el simbolismo acuático y de} fertilidad

La evidencia material en Teotihuacan es abundante en lo referente a esa relación de las piedras verdes y la idea de fertilidad, y algunos objetos de la muestra estudiada son particularmente significativos acerca de esta relación. Desde nuestro punto de vista, felinos y serpientes de piedra verde no son hechos de este material por coincidencia: los felinos, cuyo prototipo es el jaguar, es un animal mitológico identificado con el inframundo, la montaña y simbolismo del agua y la fertilidad (Von Winning 1987:
98). La serpiente es una animal identificado con la tierra, uno de los ámbitos de universo que cuando se presenta en su manifestación "emplumada", representa los dos polos del mismo (tierra y cielo) materializando el concepto de creación (idem: 125).

Los conos encontrados en la ofrenda central del Templo de Quetzalcóatl han sido interpretados como posibles representaciones de cerros (Cabrera Cortes 1995), que además del significado calendárico y agricola, se refiere al lugar de la geografia sagrada vinculado a Tlaloc o "dios de las lluvias y las tormentas" como es conocida la versión del dios para Teotihuacan.

Asociado a la misma deidad estatal están una bigotera Tlaloc y el vaso de tecalli verde, con restos de pigmento negro, azul y amarillo. Es sorprendente aquí la similitud con los patrones mexicas, en que los vasos de tezontle eran pintados de los colores que representaban los cuatro rumbos administrados por los Tlaloques - los ayudantes del dios del la lluvia. Además, Sahagún menciona que los vasos de chalchihuitl (piedra verde) pertenecian a estos pequeños ministros de Tlaloc (1975: 649). El collar de chalchihuit era igualmente un atributo de Tlaloc en el Posclásico Tardio y es posible que guardara la misma asociación entre los teotihuacanos (Jarquín 2002: 69).

El objeto fálico hecho en una roca verdosagris, y recuperado en la ofrenda 7 del Conjunto $1 \mathrm{D}$ es un ejemplo muy claro de esa asociación. Además del simbolismo expresado en su forma misma, este objeto está asociado a cuentas de piedra verde, restos de cinabrio y un brasero ceremonial, constituyendo una clara representación de elementos fríos y calientes que materializa el concepto atl-tlachinolli principio creador de la vida, expresión máxima de fertilidad y símbolo de la guerra en el Posclasico Tardio.

Las hachas ceremoniales o utilitarias, en contextos de ofrenda, pueden haber tenido un simbolismo parecido, por su posible asociación a la supervivencia, a la tierra y las actividades laborales junto a la naturaleza.

Las cuentas también podrian ser un ejemplo clásico del vínculo simbólico entre las 
piedras verdes y el agua y la fertilidad. Además de la conservación de las fuerzas anímicas representada por la cuenta en la boca del muerto, podría ser que, como en el Posclásico, dichas cuentas representaran gotas de agua o de la sangre (França 2005: 255), aunque en nuestros datos no tenemos contextos que soporten dicha interpretación.

Otro tipo de simbolismo, también vinculado al tema de la fertilidad se refiere a los ancestros y la conservación de su "fuerza". El caso de las figuras antropomorfas es muy significativo. Como vimos, las figuras grandes del Conjunto 1D, probablemente originarias de altares, presentaron rasgos olmecas y perforaciones con discos de pizarra. Según Ana Maria Jarquín dichas perforaciones representaban el ombligo de las deidades relacionadas a un culto privado de los ancestros, en este caso, los Olmecas (2002: 202).

Estamos de acuerdo con esta autora, aunque creemos que las perforaciones no necesariamente representaran ombligos, más bien lugares en que se alojaban las fuerzas anímicas, que podria ser igualmente el corazón. Es muy probable que dichas perforaciones representaran el lugar de la fuerza anímica que en el Posclásico se denominaba teyolía. Desde nuestro punto de vista, la idea sigue siendo la misma de la cuenta en la boca de los muertos como sustituto del corazón por tratarse de un claro patrón mesoamericano, observado en diferentes culturas.

Como vimos, además de corazones, las imágenes podrian tener ombligos y ojos de piedras verdes (Durán 1984, I: 24, 38). Las aplicaciones del tipo "ojo", una de ellas procedente de un entierro es un dato muy significativo.

Una de las figuras recuperadas en el mismo conjunto, en la estructura $1 \mathrm{Q}$, tenia varias perforaciones en el cuerpo (Jarquín 2002: 48) en donde estarian originalmente incrustadas piedras de jadeita o pizarra - lo que recuerda la misma idea, con la intención de "divinizar la imagen”, según el fraile español Diego de Landa, citado por la misma autora (idem).

En estos términos, creemos que en estos altares, las figuras de piedra verde y sus "piedras corazón" podrian ser interpretadas como imágenes que guardaban la fuerza de los ancestros.

La misma idea está implícita en el uso ritual de las máscaras. Según Headrick en la Calle de Muertos se entierraban los bultos de los muertos para que se preservasen su esencia, práctica vinculada al culto de los ancestros (1999: 79). En este caso las máscaras tenían una función básicamente "funeraria", como forma de preservar esta "fuerza" de los muertos, lo que no es diferente de la idea expuesta aquí. Las cabezas, aunque no presenten contexto, podrian estar incluidas en este tipo de simbolismo como posiblemente fue en el Posclásico.

El otro contexto muy importante de las figuras antropomorfas en Teotihuacan son aquellos de las ofrendas dedicatorias. En el Entierro 14 del Templo de Quetzalcóatl éstas están asociadas a los individuos sacrificados (Cabrera Cortés 1995). ¿Cuál seria su función? Cabrera Cortés cree que pudieran haber sido amuletos, o compañía a los muertos en el inframundo, o aún deidades a quienes se destinaban las ofrendas. En un estudio dedicado a los chalchihuitl entre los mexicas, sugerimos que dichas imágenes relacionadas a los cráneos decapitados en las ofrendas de consagración tenian una probable función de "esfinges", es decir, receptáculos de "almas" o fuerzas anímicas, según un patrón mesoamericano observado por López Austin acerca de otros tipos de imágenes antropomorfas (França 2005: 260-263; López Austin 1994: 169-171). Es posible que en Teotihuacan se tratara de algo semejante. Obviamente, no podemos penetrar en las particularidades de dicho fenómeno en la gran urbe, sin embargo, pensamos que dichos patrones generales - que nos son exclusivamente teotihuacanos y mexicas - son muy elocuentes, los cuales, a la luz de la documentación del siglo VXI y la abundancia de datos, nos han permitido conclusiones bastante interesantes para aquellos últimos.

Por otro lado, hay que considerar que algunas de las figuras antropomorfas de piedra verde, en especial las de estilo mezcala o Teotihuacan-guerrero, representan Tlaloc (Jarquin 2002: 182), que como se ha visto, es la 
deidad a la cual la piedra verde está particularmente asociada.

La cuenta es un objeto privilegiado dentro de este simbolismo acuático. Esta ha sido interpretada por diversas ocasiones como "gotas de agua", lo que en los contextos del Templo Mayor es absolutamente claro. Además, en algunos casos la cuenta podria representar el "agua preciosa" (chalchihuatl), es decir, la sangre del sacrificio. Para los mexicas, la piedra verde es la materialización misma de la mitad fría y femenina del cosmos y la cuenta (el chalchihuitl por excelencia) es la expresión máxima de fertilidad, ya durante su elaboración, cuando el instrumento de trabajo (metáfora del falo) realiza la "perforación", que es simbólicamente comparada a la relación sexual (França 2005: 283). Esa propiedad tan particular de máxima fertilidad, seguramente estuvo asociada al uso de las cuentas en toda el área mesoamericana para representar el "corazón" del muerto, es decir la preservación de la fuerza anímica. En Teotihuacan, lo único que tenemos son los contextos y éstos nos refuerzan ciertos patrones mesoamericanos y probablemente alguna similitud en su significado.

\section{Adornos simbólicos}

La cuenta, además de su carácter simbólico, es también un atavio. En realidad, se podría afirmar sin mucha duda que los atavíos de piedra verde presentan una doble función en los entierros: dignifican el muerto, pero también involucran significados simbólicos importantes para la ocasión.

Un ejemplo muy relevante son las orejeras. Éstas eran usadas, en las varias culturas de Mesoamérica como símbolo de estatus de miembros de la elite. Sin embargo su forma representa el disco solar, y varios ejemplares en flor y en quincunce exhiben un claro significado que está relacionado no solamente al Sol, sino también a su movimiento y a la superficie de la tierra, lo que en el caso de las sociedades mesoamericanas representaba, igualmente, el dominio politico (Brotherston 1997:125-132). La flor de cuatro pétalos era un importante símbolo religioso y politico en Teotihuacan y en el Posclásico, la palabra naxit xochitl, además de "flor de cuatro pétalos" también significaba "tetrarquia" e "imperio".

El collar, probablemente tendria un significado importante. Entre los mexicas, estaba asociado a los guerreros, linajes y antepasados, como si el sartal de cuentas materializara literalmente una hilera de nobles y guerreros, metafóricamente llamados en la poesía nahuatl chalchihuites o "jades" (França 2005: 213). La evidencia no nos permite afirmar que lo mismo se pasaba en Teotihuacan, aunque seguramente se trata de un patrón mesoamericano y es posible que hubiera algún rasgo de estas creencias.

Por alguna razón, la mayor parte de los pendientes examinados son de materiales más nobles - jadeita - y algunos de serpentina. Aunque este patrón pueda ser observado en otras sociedades de Mesoamérica, no sabemos explicar su significado, además del hecho de que los adornos, en general, son elaborados en rocas más valiosas, probablemente por una razón social y de prestigio. Quizás en el caso de los pendientes estaria la aproximación de la región del pecho y del corazón - lo que requeriría de una materia prima más noble, como el ejemplar representado en la Fig. 3.

Las narigueras "crótalo de serpiente" o "mariposa”, muy frecuentes en Teotihuacan, podrian igualmente presentar algún significado asociado a la idea de fertilidad, ya que según Cabrera Cortes, éstas estarian relacionadas al simbolismo de la serpiente emplumada (1995: 237).

\section{El enigma de las hachas}

La cuestión de los objetos utilitarios sigue siendo una incógnita. Nos sorprende la cantidad de instrumentos de trabajo y utilitarios elaborados en piedra verde y como se ha dicho, la mayor parte presenta huellas de uso. Desgraciadamente solo un hacha entre los 7 instrumentos con pigmento presenta registro de contexto parcial, sin mayores informaciones, lo que nos impide investigar sobre su significado. Una hipótesis es que podrian ser provenientes de entierros o aún ofrendas con presencia de pigmento rojo asociado a los restos humanos. 
Sin embargo, la presencia de instrumentos de trabajo en ofrenda parece un hecho excepcional, sobre todo porque no se trata de ejemplares votivos y si de objetos con rasgos de utilización. En el Entierro 14 del túnel central en el Templo de Quetzalcóatl, se encontró un ejemplar votivo de hacha de jadeita (la materia prima más noble) asociada a restos de un individuo (Cabrera Cortes 1995: 139). Una de las posibilidades sería el carácter votivo y sagrado de las hachas, fenómeno visible en diferentes culturas del planeta y relacionado al trabajo agricola y a la supervivencia y en ese sentido, el empleo de la jadeita podría ser una manera de reforzar ese simbolismo, aunque se ha propuesto que podria estar relacionada al sacrificio (idem: 299).

El caso de su presencia en los entierros parece más claro, en donde las herramientas, por lo menos aquellas con rasgos de utilización, probablemente estarian relacionadas con la ocupación de los difuntos. De todos modos, hay que considerar que la elaboración de herramientas en rocas de color verde puede ser un simple azar o simplemente por su disponibilidad, y que el simbolismo de estos objetos estén especialmente ligado a su forma, independientemente del color de la roca en hayan sido elaborados.

\section{La piedra verde y el pigmento rojo}

Otra característica importante, que seguramente estará relacionada con el contexto de deposición de los materiales es la presencia de pigmento rojo. Julie Gazzola ha llamado la atención a esa asociación de la piedra verde con el pigmento rojo que ella caracteriza como “cinabrio" (Gazzola 2000: 306). La Tabla III nos permite visualizar la frecuencia con que los objetos de jadeita y otras piedras verdes presentaron pigmento de este color. Desgraciadamente, no fue posible examinar de cerca algunas piezas citadas en inventario, ya que éstas se encontraban en vitrina o en otras exposiciones, asi que los valores abajo son aproximados.

Considerando los materiales más frecuentes, las figuras antropomorfas, cuentas, collares, orejeras e incrustaciones de mosaico e dentales y hachas son los objetos que aparecen más asociados al pigmento rojo.

$\mathrm{Al}$ contrario de lo que se podría suponer, la mayor parte de dichos objetos (por lo menos en nuestra muestra) no parecen estar particularmente asociados a entierros y desgraciadamente, la falta de datos de proveniencia no nos permite un acercamiento sistemático del problema. Entre las figuras antropomorfas con procedencia de la muestra estudiada, ninguna está asociada a entierros y entre las que presentan pigmento rojo no hay ningún ejemplar proveniente de ofrenda.

Entre las cuentas con este pigmento, 13 fueron recuperadas en entierros y una en ofrenda. Entre los tres collares, uno pertenece a un entierro, otro a una ofrenda y para el tercero ejemplar no hay registro de proveniencia. De las nueve orejeras, una estaba asociada a un entierro, y los dos tapones tenían pigmento rojo, aunque no sepamos su procedencia.

Todas las incrustaciones dentales presentaran el pigmento rojo, y por lo menos la mayor parte de las incrustaciones de mosaico, incluyendo las 55 incrustaciones del Entierro $71 \mathrm{del}$ Conjunto 1D, y otros además de rojo, el blanco.

De las hachas con pigmento, una fue recuperada en la Cala IV de La Ventilla, y solo una gubia, sin procedencia, presentó pigmentos rojo y blanco.

La presencia de pigmento rojo en gran parte de los objetos es un patrón muy importante, y según Julie Gazzola se trata de una alusión entre elementos de la fertilidad: piedra verde, símbolo de agua y fertilidad y pigmento rojo, símbolo de la sangre y renovación (2000: 383-384). Para nosotros, sin embargo, este simbolismo va más allá y nos remite nuevamente a la unión de los ámbitos cósmicos: conforme observado en los contextos de las ofrendas del Templo Mayor, las piedras verdes son un símbolo frío que representan la mitad femenina, oscura, fría del universo y el pigmento rojo (entre otros elementos "igneos" y "masculinos" con que se asocian) es un símbolo masculino, luminoso y caliente, fuente de tonalli. La unión de ambos es la materialización del concepto atl- 
Tabla III

\begin{tabular}{lrrrrrrrrrr}
\hline \multicolumn{7}{c}{ Presencia de pigmento rojo en los artefactos de piedra verde } & & \\
\hline \multicolumn{1}{c}{ Categoría } & Total & Pigmento & Ro & Bl & Ne & Am & Az & Ve & Ca & Estuco \\
\hline F. antropomorfa & 46 & 20 & 20 & 2 & 2 & - & - & - & - & - \\
Máscara & 12 & 6 & 3 & - & 5 & 1 & - & - & - & - \\
Cabeza Antrop. & 2 & 1 & 1 & - & - & - & - & - & - & - \\
F. zoomorfa & 5 & 1 & 1 & - & - & - & - & - & - & - \\
Cono & 18 & - & - & - & - & - & - & - & - & - \\
Esferita & 6 & - & - & - & - & - & - & - & - & - \\
Cuenco & 1 & - & - & - & - & - & - & - & - & - \\
Vaso Tlaloc & 1 & 1 & - & 1 & - & 1 & 1 & - & - & - \\
Objeto fálico & 1 & 1 & - & - & - & - & 1 & - & - & - \\
Aplicación & 4 & 2 & 1 & 1 & - & - & - & - & - & - \\
Esc. Simbólicas & 9 & 2 & 2 & 2 & - & - & 1 & - & - & - \\
Hacha miniatura & 1 & - & - & - & - & - & - & - & - & - \\
Cuenta & 36 & 113 & 71 & 1 & 2 & 1 & - & - & 2 & - \\
Collar & 6 & 3 & 3 & - & - & - & - & - & - & - \\
Orejera & 35 & 9 & 7 & 2 & 2 & - & 1 & - & - & 1 \\
Tapón (orejera) & 2 & 2 & 2 & - & - & - & - & - & - & - \\
Pendiente & 12 & 1 & 1 & - & - & - & - & - & - & - \\
Nariguera & 3 & 1 & 1 & - & 1 & - & - & - & - & - \\
Pectoral & 4 & - & - & - & - & - & - & - & - & - \\
Incrust. Mosaico & 90 & 89 & 89 & 5 & - & - & - & - & - & - \\
Incrust. Dental & 34 & 34 & 34 & - & - & - & - & - & - & - \\
Hacha & 19 & 6 & 4 & - & 1 & 1 & - & 1 & - & 1 \\
Gubia & 4 & 1 & 1 & 1 & - & - & - & - & - & - \\
Desfibrador & 2 & - & - & - & - & - & - & - & - & - \\
Percutor & 1 & - & - & - & - & - & - & - & - & - \\
Soporte & 2 & - & - & - & - & - & - & - & - & - \\
Pulidor & 6 & - & - & - & - & - & - & - & - & - \\
Raspador & 1 & - & - & - & - & - & - & - & - & - \\
Mano de metate & 1 & - & - & - & - & - & - & - & - & - \\
Estela & 5 & - & - & - & - & - & - & - & - & - \\
Almena & 1 & - & - & - & - & - & - & - & - & - \\
Laja & 1 & 1 & 1 & - & - & - & - & - & - & - \\
Escultura & 5 & - & - & - & - & - & - & - & - & - \\
Objeto irregular & 2 & - & - & - & - & - & - & - & - & - \\
Objeto rectangular & 2 & 1 & 1 & - & - & - & - & - & - & - \\
\hline & & & & & & & & & \\
\hline
\end{tabular}

tlachinolli, la unión de opuestos generadora de vida que mencionamos arriba.

La otra hipótesis es que en contexto funerario estos objetos se hayan mezclado con el pigmento usado en los entierros. Sin embargo, con excepción de las cuentas e incrustaciones, pocos materiales con procedencia están asociados a estos contextos - a menos que se considere casos de reutilización. Y hay que recordar siempre que esta asociación entre la piedra verde y el pigmento rojo está presente en otros contextos de la urbe y de la región mesoamericana, lo que probablemente sea resultado de algo más que un simple azar o de una mezcla de elementos dentro de un depósito funerario.

Además, en lo referente a los adornos y su papel social, hay que recordar que dichos materiales no se destacaban simplemente por 
ser de origen extranjero, o por su simbolismo de color, sino también porque en las cosmovisiones antiguas los articulos foráneos involucraban creencias asociadas al mundo sobrenatural y de los ancestros (Helms 1992: 159), hecho que refuerza la idea de que éstos eran mucho más que simples adornos, guardando simbolismos importantes relacionados a la idea de fertilidad, protección y conservación de las energias anímicas.

\section{La piedra verde y la ideología oficial}

Parece claro que esa presencia masiva de las piedras verdes en Teotihuacan resulta de la necesidad de materialización del tema central de su religión oficial, la fertilidad. Como dijimos, el simbolismo del chalchihuitl así como del color verde y su asociación con el agua, está igualmente plasmado en la pintura mural teotihuacana.

Finalmente, dicho simbolismo estaria, al igual que sus sucesores, los mexicas (obviamente con matices muy distintos), asociado al dios de la lluvia y las tormentas (Tlaloc), la deidad oficial del estado, que regia la compleja red de conceptos ligados a las aguas, la fertilidad, la supervivencia y obviamente a la ideologia estatal que manejaba la idea del control sobre la naturaleza.

La presencia de elementos arquitectónicos elaborados en piedra verde es otro rasgo que confirma la importancia de este material en el ámbito estatal.

En la esfera social, especialmente en los atavios, las piedras verdes seguramente distinguian los altos rangos, como se puede ver por los sacrificados que llevaban sus orejeras, narigueras pendientes y collares de piedra verde.

La importancia ritual y social de las piedras verdes indica claramente la existencia de una "politica" oficial en la obtención y producción de estos objetos que daban soporte a la ideologia estatal. Siguiendo la propuesta de Turner, es muy probable que las piedras verdes, sobretodo la jadeita, hayan sido trabajadas en talleres estatales o especializados (1992) posiblemente instalados en áreas cercanas a los grandes centros donde se llevaban a cabo los cultos oficiales. La misma autora utiliza el concepto de "estilo tecnológico controlado" (Controlled Technologycal Style) para referirse a una estandarización tecnológica y estilistica que caracterizaria dicha industria. La relativa homogeneidad de formas, estilos y materia prima del material lapidario de piedra verde proveniente del Templo de Quetzalcóatl, estudiado por Cabrera Cortes, puede ser un ejemplo concreto de dicho fenómeno, incluso porque se cree que fueron hechos especificamente para este evento (Cabrera Cortes 1995: 318).

Podemos proponer la existencia de una politica oficial en la obtención y producción de estos materiales, basándonos en algunos criterios e indicadores como 1. presencia y distribución en la ciudad; 2. contextos de hallazgo; 3. obtención y accesibilidad; 4 . tecnologia empleada y acabado, y se pueden sacar algunas conclusiones:

1. Desde el punto de vista de la distribución, aunque hay que considerar la desigualdad en términos de áreas excavadas, parece claro que las piedras verdes están predominantemente presentes en contextos públicos de la urbe (Cabrera Cortes 1995; Cabrera Castro y Serrano Sanchez 2003; 2002; Sugiyama 1989; Rubin de la Borbolla 1975, Jarquín 2002), y menos en los conjuntos departamentales y barrios (Manzanilla 2002, 2001, 1996; Sejourné 1959; Linné 1934, 1942; Rattray 1997; Widmer 1991), con excepción, quizás, de La Ventilla, un posible taller lapidario, donde se encontró una cantidad razonable de objetos de piedra verde (Gómez Chávez 2002).

2. La estrecha ligación de nuestras materias primas con la religión oficial teotihuacana y con elementos de las capas privilegiadas no deja duda sobre su importancia estratégica en el ejercicio del poder y la visualización de las jerarquias sociales de la urbe.

3. La jadeita, como se ha dicho es la más rara entre todas las materias primas. Hasta la fecha, la única fuente 
verdaderamente comprobada es la del Valle del Río Motagua en Guatemala (Harlow 1993: 15-16) aunque se propone su presencia en otras regiones de Mesoamérica (Pastrana 1991: 206). Esa distancia demandaba una inversión importante por parte del Estado teotihuacano en su producción, transporte y producción, lo que probablemente tenía grande importancia en el contacto hacia las lejanas tierras mayas, desde sus principios. Como se ha visto, dicha materia prima en su mayor parte era destinada a los atavios, presentando, por tanto un uso predominantemente social.

Las demás piedras verdes, como la serpentina, la fuchsita, el cuarzo y tecalli verdoso podrian ser obtenidas en varios puntos de Mesoamerica, como en los actuales estados de Guerrero, Puebla, Oaxaca, Chiapas, Veracruz e Hidalgo (González y Olmedo Vera 1986b: 80-81; Cabrera Cortes 1995: 320). Aquí, aunque la disponibilidad fuera un poco más amplia, y los estudios demuestran que parte de los materiales provenian de la cuenca del Río Mezcala y Balsas, en el actual estado mexicano de Guerrero, es posible que otros estados hayan sido responsables por su aprovisionamiento; si por la vía de comercio u obtención directa, no lo sabemos. De todos modos hay que considerar una inversión razonable en la obtención de éstas materias primas y objetos importados.

4. La jadeita es uno de los materiales más duros en la naturaleza alcanzando de 6.5 a 7 en la escala de Moh, lo que significa que la elaboración de objetos de jadeita requiere de un conjunto de técnicas muy especializadas. Ese es más un argumento a favor de la existencia de talleres especializados para los objetos confeccionados con esa materia-prima. Además, como bien observa Turner 1992: 95), en los talleres de barrio casi no se encuentran desechos de este material, lo que también puede ser debido a su alto valor que hacía con que las más pequeñas lascas fueron utilizadas, como sucedió en otras partes de Mesoamerica (González y Olmedo Vera 1986a: 89).

Las piedras verdes, con distintos niveles de estructura y dureza, seguramente requerian menos esfuerzo en su trabajo, aunque si posiblemente conservaron una convención en sus estilos y caracteristicas, observables en el conjunto de los materiales.

Por último, un aspecto importante es lo de la cronología. Desgraciadamente, los datos recolectados no nos permiten hacer un inventario sistemático y preciso de la cuestión, dejándonos solamente la posibilidad de una apreciación limitada.

Desde el punto de vista de la muestra estudiada tenemos materiales procedentes de estructuras fechadas en las diversas fases de desarrollo de la ciudad, que se extiende desde las fases más antiguas, con la inauguración de los grandes edificios públicos en la fase Tzacualli (0150 d.C.) hasta la fase Metepec (550-650 d.C), incluyendo los conjuntos departamentales y Calle de Muertos que inician sus actividades a partir del Tlamimilolpa Temprano (200-300 d.C.).

Aunque la muestra estudiada y la información disponible sea escasa, sabemos que edificios tempranos como las Pirámides del Sol y de la Luna y el Templo de Quetzalcóatl, presentaron muchos objetos de piedra verde (Cabrera Castro y Serrano Sánchez 2003; Cabrera Castro 2002; Cabrera Cortés 1995; Sugiyama 1989; Rubin de la Borbolla 1975). Otros espacios inaugurados en la fase Tlamimilolpa Temprano como Calle de Muertos y los conjuntos departamentales también seguian el uso de dicho material, guardadas las diferencias "funcionales" de los edificios. En el conjunto 1D cuyas actividades siguieron hasta la fase Metepec fueron recuperados, como fue dicho, muchos objetos simbólicos de piedra verde. Sin embargo, no deja de ser significativo que los edificios públicos con mayores cantidades de piedra verde pertenecen en su mayoria a las fases tempranas, lo que indica que en éstas fechas el comercio de dicho material era ya sumamente desarrollado. 
A la primera vista se puede hablar de un uso continuo de las piedras verdes durante la historia de la ciudad, aunque sus matices temporales en lo referente su intensidad o simbolismo solo podrian ser investigadas a partir de un conjunto de datos muy detallados. En su estudio, M. Sempowski observó la ausencia de dichos materiales en los entierros de capas sociales intermedias de la fase Metepec (1992: 46) y aunque dichos contextos sean bien diversos de los abordados en este artículo, hay que prestar atención a sus resultados. Por su importancia simbólica y social, la jadeita y las piedras verdes estuvieron asociadas prioritariamente a contextos estatales de Teotihuacan, y es muy probable que la desagregación del aparato estatal en su último siglo de existencia, y el consecuente colapso del comercio de larga distancia haya resultado en una disminución drástica del consumo de dichas materias primas $y$, por consecuencia, del soporte a una ideología que poco a poco era objeto de duda por parte de la población teotihuacana.

\section{Agradecimientos}

Mis agradecimientos al INAH y la ZMATZona de Monumentos Arqueológicos de Teotihuacan por brindarme el acceso a los materiales; a Ruben Cabrera por el apoyo en la investigación, Miguel Morales por las fotos, Nestor Paredes, Raul Rojas y Roberto Rojas Beltrán por el apoyo con los materiales y al CNPq-Conselho Nacional de Desenvolvimento Científico e Tecnológico del Ministério de Ciência e Tecnologia de Brasil, por la beca Postdoctoral que hizo posible esta investigación.

FRANÇA, L.M. The jade and the greenstones in Teotihuacan, Mexico. Revista do Museu de Arqueologia e Etnologia, São Paulo, 20: 327-344, 2010.

Abstract: Jade was one of the most valuable materials in Mesoamerica, and it was used to make many objects, like gods images, religious objects, jewelry and ornaments, among many others. In Teotihuacan jade and greenstones played a key role in the ornamentation of the elite and rituals, reflecting fundamental concepts of cosmology and the state religion. This article attempts to provide details on the symbolism of jade in Teotihuacan, its ideological role and control over its procurement and production of artifacts, from the study of jade and greestone artifacts preserved in the Ceramoteca of the Zona de Monumentos Arqueológicos de Teotihuacan.

Keywords: Teotihuacan - Mesoamerica - Mexico - Jade - Ideology.

\section{Referencias bibliográficas}

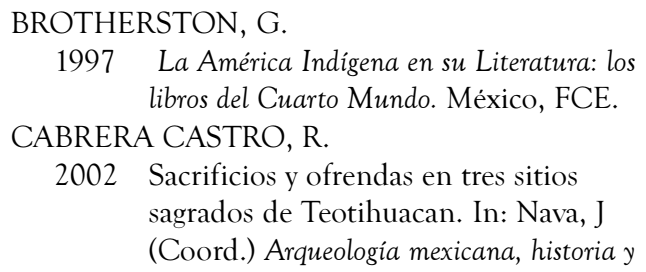

esencia. Siglo XX. INAH, Colección

Cientifica: 107-117.

CABRERA CASTRO, R.; SERRANO SÁNCHEZ, C.

2003 Los entierros de la Pirámide del Sol y Templo de Quetzalcóatl. In: Manzanilla, L; C. Serrano (Eds.) Prácticas Funerarias en la Ciudad de los Dioses. Los enterramientos 
humanos de la antigua Teotihuacan. México, IIA/UNAM: 345-397

CABRERA CORTÉS, M.O.

1995 La Lapidaria del Proyecto Templo de Quetzalcóatl 1988-1989, México, ENAH.

COVARRUBIAS, $\mathrm{M}$.

1961 El Águila, el Jaguar y la Serpiente. Arte Indigena Americano. México,UNAM.

DURÁN, D. F.

1984 Historia de las Indias de Nueva España e Islas de la Tierra Firme (Ed. Angel Maria Garibay K.). 2 Vol. México, Editorial Porrua.

FRANCุA, L.

2005 O monte das águas-queimadas: o simbolismo das oferendas no Templo Mayor de Tenochtitlan, México Tese de Doutorado, São Paulo, MAE/USP.

FREIDEL, D.

1993 The Jade Ahau. Toward a Theory of Commodity Value in Maya Civilizations. In: Lange, F (Ed.) Precolumbian Jade. New Geological and Cultural Interpretations. Salt Lake City, University of Utah Press: 149. 165.

FOSHAG, W.

1953-54Estudios mineralógicos sobre el jade de Guatemala. In: Antropología e Historia de Guatemala. R3400. Vol. 5-6:3-49.

GARBER. J. F.; GROVE, D.C.; HIRTH, K.G.; HOOPES, J.W.

1993 Jade Use in Portions of Mexico and Central America: Olmec, Maya, Costa Rica, and Honduras - A Summary. In: Lange, F (Ed.) Precolumbian Jade. New Geological and Cultural Interpretations. Salt Lake City, University of Utah Press: 211 231.

GAZZOLA, J.

2000 Los usos de cinabrio en Teotihuacan. Tese de Doctorado, Sorbonne, Paris I.

GÓMEZ CHÁVEZ, S.

2000 La Ventilla. Un barrio de la antigua ciudad de Teotihuacan. Tese de Licenciatura. México, ENAH/INAH.

GONZÁLEZ, C.; OLMEDO VERA, B.

1986a Áreas de actividad relacionadas con el trabajo del jade. In Manzanilla, L. (Ed.) Unidades Habitacionales Mesoamericanas y sus áreas de actividad. México, UNAM: 75 102.

1986b Presencia del estilo mezcala en el Templo Mayor de Tenochtitlan: uma clasificación de piezas antropomorfas. Tesis de licenciatura. México, ENAH.

HARLOW, G.E.

1993 Middle American Jade. Geologic and Petrologic Perspectives on Variability and Source. In: Lange, F. (Ed.) Precolumbian Jade. New Geological and Cultural Interpretations. Salt Lake City, University of Utah Press: 9-20.

HEADRICK, A.

1999 The street of the dead...it really was. In: Ancient Mesoamerica, 10: 69-85.

HELMS, M.W.

1992 Long-Distance Contacts, Elite Aspirations, and the Age of Discovery in Cosmological Context. In: Schortman, E.M; Urban, P. A (Eds.) Resources, Power, and Interregional Interaction. New York, Plenum Press: $157-$ 174.

HERNÁNDEZ PONS, E.C.

1982 Sobre un conjunto de esculturas asociadas a las escalinatas del Templo Mayor. In: Matos Moctezuma, E (Ed.) El Templo Mayor: excavaciones y estudios. México, INAH: 212-232.

JARQUÍN P., A.M.

2002 El Conjunto Norte y Lado Este de la Ciudadela: análisis de contextos arqueológicos del Periodo Clásico desde la perspectiva de la Etnohistoria. México: FFL/IIF-UNAM.

LANGE, F.

1993 Introduction. In: Lange, F. (Ed.)

Precolumbian Jade. New Geological and Cultural Interpretations. Salt Lake City, University of Utah Press: 1-6.

LINNÉ, S.

1934 Archaeological Researches at Teotihuacan, México. Stockholm, Ethnographic Museum at Sweden, n. s., Publ. 1.

1942 Mexican highlands cultures: archaeological researches at Teotihuacan, Calpulalpan and Chalchicomula in 1934-35. Stockholm, Ethnographical Museum of Sweden, n.s, Pub. 7.

LÓPEZ AUSTIN, A.

1994 La cosmovisión mesoamericana. In: Lombardo, S.; Nalda, E. (Coords.) Temas Mesoamericanos. México, INAH-CNCA: 471-507.

1996 Cuerpo Humano e Ideología. Las concepciones de los antiguos nahuas. México, UNAM.

MANZANILLA, L.

1996 Corporate Groups and Domestic Architecture at Teotihuacán. Latin American Antiquity, 7 (3): 228-246. 
2001 Teopancazco, un conjunto residencial de Teotihuacan. In: Tezontle. Boletin del Centro de Estudios Teotihuacanos, 5 , Abril, Mayo, Junio: 2-4.

2002 Living with the Ancestors and Offering to the Gods. Domestic Ritual at Teotihuacan. In: Plunket, P. (Ed.) Domestic Ritual in Ancient Mesoamerica. Los Angeles, University of California: 43-53.

MILLER, E.

1991 The Art of Mesoamerica from Olmec to Aztec. London, Thames and Hudson.

MILLÓN, E.

1973 Urbanization at Teotihuacan. Teotihuacan Mapping Project. Austin, University Texas Press.

MIRAMBELL, L.

1968 Técnicas Lapidarias Prehispánicas. México, INAH: 27-28.

PASZTORY, E.

1992 Abstraction and the Rise of a Utopian State at Teotihuacan. In: Berlo, J. (Ed.) Art, Ideology and the City of Teotihuacan. Washington, D.C., Dumbarton Oaks: 281-320.

PASTRANA, A.

1991 Sobre el jade y rocas verdes en el México Prehispánico. In: Barba, B.; Garcia, A.; Macias, A.; Valle, P.; Cardós, A.; Islas, C.; Pérez-Rocha, E. Homenaje a Julio César Olivé Negrete. México, UNAM-CONACULTAINAH-Colegio Mexicanos de Antropólogos: 195-208.

RATTRAY, E.

1997 Entierros y Ofrendas en Teotihuacan. Excavaciones, inventario, patrones mortuorios. México, IIA/UNAM.

RUBIN DE LA BORBOLLA, D.F.

1974 Teotihuacan: ofrendas de los Templos de Quetzalcóatl. In: Anales, INAH, II: 61-72.

SAHAGÚN, B.

1975 Historia General de las Cosas de la Nueva SEJOURNÉ, L. España. México, Editorial Porrua.

1959 Un Palacio en la Ciudad de los Dioses, Teotihuacan. México, INAH.
SEMPOWSKI, M.

1992 Economic and Social Implications of Variations in Mortuary Practices at Teotihuacan. In: Berlo, J.C. (Ed.) Art, Ideology and the City of Teotihuacan. A Symposium at Dumbarton Oaks, $8^{\text {th }}$ and $9^{\text {th }}$ October, 1988. Washington, D.C., Dumbarton Oaks: 27-58.

STONE, D. Z.

1993 Jade and Jade objects in Precolumbian Costa Rica. In: Lange, F. (Ed.) Precolumbian Jade. New Geological and Cultural Interpretations. Salt Lake City, University of Utah Press: 141-148.

SUGIYAMA, S.

1989 Burials dedicated to the Old Temple of Quetzalcóatl at Teotihuacan, México. American Antiquity, 54 (1): 95-106.

TAUBE, K. A.

2005 The Symbolism of Jade in Classic Maya Region. Ancient Mesoamerica, 16: 23-50.

THOUVENOT, M.

1982 Chalchihuitl. Le jade chez les Aztéques. Museúm National d'Historie Naturelle Mémoires de I'Institut d'Etnologie-XXI. Institute d'Éthnologie -Musée de L'Homme.

TIBÓN, G.

1983 El jade de México: el mundo esotérico del 'chalchihuite'. México, Panorama Editorial. (1" Ed. 1905).

TURNER, M.

1992 Style in Lapidary Technology: Identifying the Teotihuacan Lapidary Industry. In: Berlo, J.C. (Ed.) Art, Ideology and the City of Teotihuacan. Washington, D.C., Dumbarton Oaks: 89-112.

\section{VON WINNING}

1987 La Iconografía de Teotihuacan. Los dioses y los signos. México, UNAM, 2 tomos.

WIDMER, R.J.

1991 Lapidary craft specialization at Teotihuacan. Implications for community structure at 33:S3W1 and Economic Organization in the city. In: Ancient Mesoamerica, 2 (1): 131-147. 